\title{
PERBEDAAN PENURUNAN INTENSITAS NYERI DISMENOREA PADA REMAJA DENGAN MENGGUNAKAN RELAKSASI NAFAS DALAM DAN RELAKSASI IMAJINASI TERMBIMBING
}

\author{
Hotma Sauhur Hutagaol \\ PRODI KEBIDANAN PADANGSIDIMPUAN
}

\begin{abstract}
Abstrak
Dismenorea adalah nyeri yang berhubungan dengan menstruasi. Dismenorea adalah salah satu dari penyebab tersering dari nyeri panggul. Dan secara negatif mempengaruhi kualitas hidup seseorang dan terkadang menghasilkan dalam penurunan aktifitas. Teknik relaksasi merupakan salah satu alternatif penatalaksanaan dismenorea. Tujuan penelitian ini adalah untuk menganalisis perbedaan penurunan intenstias nyeri dismenore pada remaja dengan menggunakan relaksasi nafas dalam dan relaksasi imajinasi terbimbing. Penelitian ini merupakan penelitian kuantitatif dengan disain quasi experimental dengan pre and post test goup design untuk mengetahui perbedaan penurunan intensitas nyeri dismenorea dengan menggunakan relaksasi nafas dalam dan relaksasi imajinasi terbimbing. Data dianalisa menggunakan uji Mann_Whitney, dan nilai $p<0.05$ dianggap bermakna secara statistik. Setelah dilakukan relaksasi nafas dalam dan relaksasi imajinasi terbimbing didapati hasil penurunan rerata nyeri menstruasi pada kelompok relaksasi imajinasi terbimbing lebih besar dibandingkan penurunan rerata nyeri menstruasi pada kelompok relaksasi nafas dalam. Dari hasil penelitian dapat disimpulkan bahwa terdapat perbedaan penurunan relaksasi nafas dalam dibandingkan dengan relaksasi imajinasi terbimbing terhadap nyeri menstruasi.
\end{abstract}

Kata kunci: Relaksasi Nafas Dalam, Relaksasi Imajinasi Terbimbing, Nyeri Menstruasi

\section{PENDAHULUAN}

\section{Latar Belakang}

Dismenorea adalah nyeri yang berhubungan dengan menstruasi. Lebih dari 1.5 wanita yang mengalami menstruasi merasakan nyeri 1-2 hari setiap bulan. Nyeri menstruasi biasanya terjadi sesaat sebelum menstruasi terjadi. Hal ini terjadi karena peningkatan hormon prostaglandin pada hari pertama periode menstruasi. Saat menstruasi terus berlanjut maka semakin hari kadar prostaglandin akan menurun dan rasa nyeri juga akan menurun. Sering kali nyeri menstruasi dirasakan oleh wanita saat permulaan masa menstruasi dan akan menurun seiring dengan bertambahnya usia. Oleh karena itu remaja akan lebih rentan mengalami nyeri menstruasi dibandingkan dengan wanita dewasa (ACOG, 2015).

Dismenorea adalah salah satu dari penyebab tersering dari nyeri panggul. Dan secara negatif mempengaruhi kualitas hidup seseorang dan terkadang menghasilkan dalam penurunan aktifitas. Dismenorea terbagi dua yaitu dismenorea primer dan dismenorea sekunder. Dismenorea primer adalah nyeri menstruasi yang tidak disertai keadaan patologi dari panggul atau rahim (Osayande, 2014).

Wanita yang mengalami nyeri menstruasi (dismenorea) memproduksi prostaglandin 10 kali lebih banyak dari wanita yang tidak dismenorea. Prostaglandin menyebabkan meningkatnya kontraksi uterus, dan pada kadar yang berlebih akan mengaktivasi usus besar (Johnston, 2014).
Dismenorea adalah gangguan menstruasi yang ditandai dengan nyeri berupa kram di daerah perut bagian bawah, yang diikuti dengan terkadang diikuti dengan muntah, diare, pusing atau pingsan. Dismenorea terjadi pada 20 - $90 \%$ remaja wanita dan berakibat berat pada 14 - $42 \%$ remaja, yang membuat remaja tidak dapat bersekolah atau kerja (Sayre, 2008).

Di lingkungan SMAN 1 Sayur Matinggi Kabupaten Tapanuli Selatan diperkirakan 20\% siswi mengalami nyeri menstruasi pada saat menstruasi dan sekitar 6\% siswi SMAN 1 Sayur Matinggi tidak bisa melakukan aktivitas seperti biasanya disebabkan nyeri menstruasi (Survei, 2016).

Salah satu alternatif pengobatan dismenorea adalah dengan teknik relaksasi (ACOG, 2015). Terdapat beberapa teknik relaksasi, yaitu teknik relaksasi nafas dalam dan teknik relaksasi imajinasi terbimbing, yang salah satu tujuannya adalah memberikan rasa relaksasi sehingga terjadi penurunan rasa nyeri.

Relaksasi nafas dalam secara fisiologi meningkatkan aliran darah ke jaringan tubuh, menurunkan rasa nyeri dan kecemasan (Heni, 2017).

Relaksasi imajinasi terbimbing adalah metode relaksasi untuk menghayalkan tempat dan kejadian berhubungan dengan relaksasi yang menyenangkan. Khayalan tersebut memungkinkan klien untuk memasuki keadaan atau pengalaman relaksasi (ACOG, 2006).

Oleh karena itu penelitian ini bertujuan menganalisis efektivitas relaksasi nafas dalam dan imajinasi terbimbing terhadap nyeri menstruasi. 


\subsection{Tujuan Penulisan}

a. Tujuan Umum: Untuk mengetahui efektivitas relaksasi nafas dalam dan relaksasi imajinasi terbimbing terhadap nyeri menstruasi pada remaja.

b. Tujuan Khusus

a. Untuk mengetahui intensitas nyeri menstruasi sebelum dan sesudah dilakukan relaksasi imajinasi terbimbing pada kelompok intervensi.

b. Untuk mengetahui intensitas nyeri menstruasi sebelum dan sesudah dilakukan relaksasi nafas dalam pada kelompok intervensi.

c. Untuk mengetahui perbedaan intensitas nyeri menstruasi pada kelompok relaksasi nafas dalam dan relaksasi imajinasi terbimbing.

\subsection{Hipothesis}

1. Terdapat perbedaan efektivitas relaksasi nafas dalam dan relaksasi imajinasi terbimbing terhadap nyeri menstruasi pada remaja.

\subsection{Manfaat Penelitian}

a. Manfaat Akademik

Diharapkan penelitian ini dapat memberikan sumbangsih akademik mengetahui perbedaan efektivitas relaksasi nafas dalam dan relaksasi imajinasi terbimbing terhadap penurunan intensitas nyeri menstruasi pada remaja.

b. Manfaat Terapan

Diharapkan hasil penelitian ini dapat menjadi bahan masukan pada para bidan dalam memberikan asuhan kebidanan reproduksi pada remaja dengan nyeri menstruasi dengan menggunakan perlakukan relaksasi nafas dalam dan relaksasi imajinasi terbimbing.

\section{METODE PENELITIAN}

\subsection{Jenis Penelitian}

Jenis penelitian ini adalah bersifat analitik menggunakan studi quasi eksperimental, yang bertujuan untuk mengetahui pengaruh relaksasi imajinasi terbimbing terhadap nyeri menstruasi. Desain penelitian adalah pre test and post test group design.

Populasi penelitian ini adalah semua remaja dengan nyeri menstruasi di SMAN 1 Sayur Matinggi. Subjek penelitian yang dipilih adalah semua populasi yang memenuhi kriteria inklusi dan eksklusi. Kriteria inklusi dalam penelitian ini adalah remaja dengan nyeri menstruasi. Kriteria eksklusi adalah mengkonsumsi obat penghilang nyeri atau jamu.

Jumlah sampel dihitung dengan menggunakan rumus perhitungan sampel dengan metode penelitian quasy eksperimen. Simpang baku kedua kelompok perlakuan adalah 1,75 (Wirya, 2013).

Besar sampel dihitung dengan rumus dari Sastroasmoro:

$$
\mathrm{n} 1=\mathrm{n} 2=2[(z \alpha+z \beta) x s]^{2}
$$

$$
\left(\mathrm{x}_{1}-\mathrm{X}_{2}\right)
$$

$\mathrm{s}=$ simpang baku nilai rerata dalam populasi, $(1,75)$ dari penelitian terdahulu (Wirya, 2013)

$\mathrm{x}_{1}-\mathrm{X}_{2}=1$

$\alpha=$ tingkat kemaknaan $95 \%$

$\mathrm{n} 1=\mathrm{n} 2=2[(1,96+1,282) \times 1,75]^{2}$

$(5-3)$

$=16$ orang

Data yang dikumpulkan dianalisis dengan menggunakan analisis univariat dan analisis bivariat untuk mengetahui hubungan variabel independen dengan variabel dependen dengan pengujian uji- $t$ berpasangan. Analisis bivariat digunakan untuk menyatakan analisis terhadap dua variabel yaitu variabel bebas dan variabel tergantung dengan menggunakan uji-t berpasangan dengan interval kepercayaan $95 \%(\alpha=0,05)$ bila $\mathrm{p}<0,05$ maka variabel dinyatakan signifikan. Penyajian data dalam bentuk tabel dan grafik.

\subsection{Metode Pengumpulan Data}

Metode pengumpulan data yang digunakan peneliti untuk mengumpulkan data adalah data primer dengan menggunakan lembar observasi yang diisi oleh subjek penelitian.

\subsection{Metode Analisa Data}

Data yang dikumpulkan dianalisis dengan menggunakan analisis bivariat untuk mengetahui hubungan variable independen dengan variable dependen dengan pengujian $t$-test untuk intensitas nyeri menstruasi.

\subsection{Definisi operasional}

Untuk lebih menjelaskan dan menghindari kesalahan penafsiran beberapa kata/istilah dalam penelitian ini, peneliti merumuskan definisi operasional kata/istilah tersebut berikut ini.

1. Relaksasi nafas dalam

Defenisi : Relaksasi adalah status hilang dari ketegangan otot rangka dimana individu mencapainya melalui praktek nafas dalam yang disengaja (Smeltzer, 2002).

Cara ukur : melakukan nafas dalam dan lambat lewat hidung (menahan inspirasi secara maksimal) dan mengeluarkan nafas perlahanlahan

lewat mulut.

Alat ukur : lembar observasi

Hasil ukur: Sebelum dilakukan relaksasi nafas dalam diberi nilai 0 , setelah dilakukan diberi

nilai 1

Skala ukur : Nominal

2. Relaksasi imajinasi terbimbing

Defenisi : Relaksasi imajinasi terbimbing adalah metode relaksasi untuk menghayalkan tempat dan kejadian berhubungan dengan relaksasi yang menyenangkan (Kaplan, 2010).

Cara ukur : membayangkan kondisi yang santai atau tentang 
pengalaman yang menyenangkan.

Alat ukur : lembar observasi

Hasil ukur: Sebelum dilakukan relaksasi imajinasi terbimbing diberi nilai 0 , setelah dilakukan diberi nilai 1

Skala ukur : Nominal

3. Nyeri Menstruasi

Defenisi : Nyeri saat haid yang dirasakan responden yang terletak pada perut bagian bawah yang timbul tidak lama sebelum atau bersamaan dengan permulaan haid yang berlangsung beberapa jam atau sampai berhari-hari.

Cara ukur : Mengukur tingkat nyeri

Alat ukur : Skala nyeri NRS (skala nyeri numeric)

Hasil ukur : Tingkat Nyeri

Skala ukur : Interval

\section{HASIL PENELITIAN DAN PEMBAHASAN}

\subsection{Hasil Penelitian}

Penelitian ini dilakukan mulai Oktober 2016 sampai Agustus 2017. Sampel yang memenuhi kriteria inklusi dan eksklusi sebanyak 16 orang per kelompok. Kemudian dilakukan pretest untuk mengetahui intensitas nyeri. Dengan menggunakan lembar observasi dihitung pola menstruasi selama ini yaitu siklus dan lama menstruasi. Setelah itu pada kelompok pertama dilakukan relaksasi nafas dalam, kemudian pada kelompok kedua dilakukan relaksasi imajinasi terbimbing mulai hari pertama haid sampai hari terahir haid dan diukur kembali intensitas nyeri dengan menggunakan kuesioner skala nyeri numerik. Pola menstruasi dihitung kembali dengan menggunakan lembar observasi. Pelaksanaan penelitian ini dilakukan oleh responden langsung setelah mendapatkan pelatihan dari peneliti. Setiap pagi peneliti mengingatkan setiap responden untuk melaksanakan relaksasi nafas dalam pada kelompok pertama dan relaksasi imajinasi terbimbing pada kelompok kedua. Waktu yang dibutuhkan untuk satu orang responden adalah sekitar 5 - 10 menit untuk perlakuan.

\section{Tabel 1 Karakteristik Responden}

\begin{tabular}{llcc}
\hline $\begin{array}{l}\text { Karakterist } \\
\text { ik }\end{array}$ & $\begin{array}{c}\text { K.Pertama } \\
\text { Rerata } \pm \text { SD }\end{array}$ & $\begin{array}{c}\text { K.Kedua } \\
\text { Rerata } \pm \text { SD }\end{array}$ & $p$ \\
\hline Umur & $14,3 \pm 0,6$ & $14,3 \pm 0,4$ & $p>0,05$ \\
Umur & $13,1 \pm 0,7$ & $13,2 \pm \mathbf{0 , 3}$ & $p>0,05$ \\
$\begin{array}{l}\text { Menarche } \\
\begin{array}{l}\text { Intensitas } \\
\text { nyeri }\end{array}\end{array}$ & $6,6 \pm 1,6$ & $6,6 \pm 1,8$ & $p>0,05$ \\
\hline
\end{tabular}

Dari tabel 1 diketahui bahwa karakteristik responden tidak terdapat perbedaan pada kelompok pertama dan kelompok kedua untuk rerata umur, umur menarche, intensitas nyeri sebelum dilaksanakan perlakuan dengan nilai $p>0,05$.

\section{Analisis Bivariat}

Analisis bivariat dilakukan untuk mengetahui perbedaan efektivitas relaksasi nafas dalam dan relaksasi imajinasi terbimbing terhadap intensitas nyeri menstruasi dengan menggunakan analisis Uji Mann-Whitney. Hasil analisis bivariat dalam penelitian ini adalah sebagai berikut:

Tabel 2 Hasil Analisa Efektivitas Relaksasi Nafas Dalam dan Relaksasi imajinasi terbimbing Terhadap Intensitas Nyeri menstruasi

\begin{tabular}{llc}
\hline Intensitas Nyeri & Rerata \pm SD & $p$ \\
\hline K.Pertama & $4,2 \pm 0,4$ & 0,001 \\
K.Kedua & $2,2 \pm 0,2$ & \\
\hline
\end{tabular}

Tabel 2 menunjukkan perbedaan intensitas nyeri menstruasi pada kelompok relaksasi nafas dalam dan kelompok relaksasi imajinasi terbimbing. Rerata intensitas nyeri menstruasi pada kelompok relaksasi nafas dalam sebelum perlakuan adalah $6,6 \pm 1,6$ menjadi 4,2 $\pm 0,4$ setelah dilakukan relaksasi nafas dalam. Rerata intensitas nyeri menstruasi pada kelompok relaksasi imajinasi terbimbing sebelum perlakuan adalah $6,6 \pm 1,8$ menjadi 2,2 $\pm 0,2$ setelah dilakukan relaksasi imajinasi terbimbing.

Secara statistik dengan uji mann_whitney terdapat perbedaan bermakna dengan $p$ value $0,001(<0,05)$.

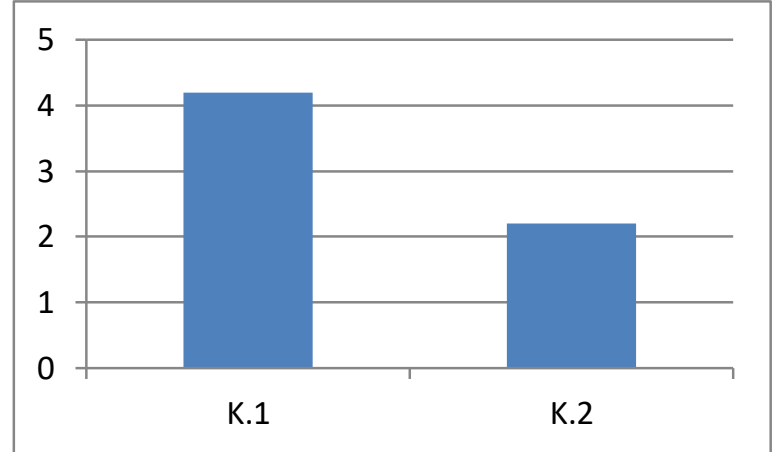

Gambar 1. Rerata Intensitas Nyeri Menstruasi Pada Kelompok Pertama (Relaksasi Nafas Dalam) dan Kelompok Kedua (Relaksasi Imajinasi Terbimbing)

\subsection{Pembahasan}

Pada penelitian ini didapatkan hasil terdapat perbedaan intensitas nyeri menstruasi pada kedua kelompok setelah dilakukan relaksasi nafas dalam dan relaksasi imajinasi terbimbing. Intensitas nyeri menstruasi mengalami penurunan lebih banyak pada kelompok kedua (relaksasi imajinasi terbimbing) dibandingkan kelompok pertama (relaksasi nafas dalam). Rerata intensitas nyeri menstruasi atau dismenorea pada kelompok pertama (relaksasi nafas dalam) menurun dari 6,6 \pm 1,6 menjadi 4,2 $\pm 0,4$ sedangkan pada kelompok kedua (relaksasi imajinasi terbimbing) rerata intensitas nyeri menstruasi menurun dari $6,6 \pm 1,8$ menjadi $2,2 \pm 0,2$ setelah dilakukan relaksasi imajinasi terbimbing.

Setelah dilakukan relaksasi imajinasi terbimbing rerata intensitas nyeri menstruasi pada kelompok perlakuan lebih rendah dibandingkan dengan kelompok kontrol. Secara statistik dengan uji $\mathrm{t}$ berpasangan terdapat perbedaan bermakna dengan $p$ value $0,001(<0,05)$. 
Hal ini menunjukkan bahwa pemberian relaksasi imajinasi terbimbing memiliki pengaruh yang lebih baik terhadap penurunan intensitas nyeri menstruasi.

Prinsip yang mendasari penurunan nyeri oleh relaksasi terletak pada fisiologi system saraf otonom yang merupakan bagian dari sistem saraf perifer yang mempertahankan homeostatis lingkungan internal indvidu. Pada saat terjadi pelepasan mediator seperti bradikilin, prostagandin dan substansi $\mathrm{p}$, akan merangsang saraf simpatis sehingga menyebabkan vasokonstriksi yang akhirnya meningkatkan tonus otot yang menimbulkan berbagai efek seperti spasme otot yang akhirnya menekan pembuluh darah, mengurangi aliran darah dan meningkatkan kecepatan metabolisme otot yang menimbulkan pengiriman impuls nyeri dari medulla spinalis ke otak akan dipersepsikan sebagai nyeri (Tamsuri, 2007).

Dengan merelaksasikan otot- otot skelet yang mengalami spasme yang disebabkan oleh peningkatan prostaglandin sehingga terjadi vasodilatasi pembuluh darah dan akan meningkatkan aliran darah ke daerah yang mengalami spasme dan iskemik (Smeltzer, 2002).

Novarenta dalam penelitiannya terhadap tiga orang responden dengan nyeri berat menstruasi mendapatkan hasil setelah dilakukan relaksasi imajinasi terbimbing terjadi penurunan intensitas nyeri menjadi nyeri ringan (Novarenta, 2013).

Relaksasi imajinasi terbimbing dengan menghayalkan situasi yang menyenangkan dengan visualisasi mampu merangsang tubuh untuk melepaskan opoiod endogen yaitu endorphin dan enkefalin. Hormon ini akan memberikan pengaruh terhadap penurunan rasa nyeri.

\section{KESIMPULAN DAN SARAN}

\subsection{Kesimpulan}

1. Dari hasil penelitian berdasarkan hasil analisis bivariat dengan menggunakan uji Mann_Whitney didapatkan adanya perbedaan nilai rerata intensitas nyeri menstruasi pada kelompok pertama (relaksasi nafas dalam) dan kelompok kedua (relaksasi imajinasi terbimbing), yaitu intensitas nyeri menstruasi lebih rendah pada kelompok relaksasi imajinasi terbimbing dibandingkan kelompok relaksasi nafas dalam.

2. Dari hasil analisis statistik dengan menggunakan uji Mann_Whitney didapatkan nilai $\mathrm{P}=0,001<\alpha=0,05$ dimana ada perbedaan bermakna antara nyeri menstruasi antara kelompok pertama dan kelompok kedua, maka dapat disimpulkan bahwa ada perbedaan efektivitas penurunan intensitas nyeri menstruasi pada kelompok relaksasi nafas dalam dan kelompok relaksasi imajinasi terbimbing yang signifikan terhadap penurunan intensitas nyeri menstruasi pada remaja.
5.2. Saran

1. Perlunya sosialisasi berkelanjutan kepada remaja untuk penatalaksanaan nyeri menstruasi sehingga akan diperoleh hasil yang optimal.

2. Perlunya pendekatan berkesinambungan kepada remaja untuk menanamkan pentingnya pelaksanaan teknik relaksasi terhadap penurunan intensitas nyeri menstruasi.

\section{DAFTAR PUSTAKA}

ACOG, 2015. Dysmenorrhoea, Painful Periods. FAQ046.

Arikunto, S. 2003. Prosedur Penelitian: Suatu Pendekatan Praktek . Edisi IV. Jakarta: Rineka Cipta.

Heni Apriyani, Sono, The Influence Of Deep Breathing Relaxation Technique On Nauseous Scale In Gastrointestinal Disorders Patients. Proceeding International Conference On Inter Professional Collaboration 2017. Jakarta: Poltekkes Jakarta 3.

Novarenta A, 2013. Guided Imagery Untuk Mengurangi Rasa Nyeri Saat Menstruasi. Jurnal Ilmiah Psikologi Terapan. ISSN: 2301-8267 Vol 01, No.02 Agustus, 2013. Fak Psikologi Univ.Muhammadiyah Malang

Osayande S, Mehulic S. 2014. Diagnosis and Initial Management of Dysmenorrhea. Am Fam Physician. 2014;89(5):341-346.

Perry, AG, Potter PA .2005. Buku Ajar Fundamental Keperawatan;Konsep, Proses dan Praktik , Vol.2 Alih Bahasa. Editor Monica Ester Dkk, Jakarta : EGC

Poornima, 2015. The Effects of Classical Music based Chakra Meditation on the Symptoms of Premenstrual Syndrome. The International Journal of Indian Psychology ISSN 2348-5396 (e) | ISSN: 2349-3429 (p) Volume 2, Issue 3.

Sayre C. 2008. Taming Menstrual Cramps In Adolescents.Http://Www.Nytimes.Com/Ref/ Health/Healthguide/Esn-MenstrualcrampsEss.Html

Sastroasmoro S. 2011. Dasar-dasar Metodologi penelitian klinis. Jakarta: CV.Sagung seto.

Smeltzer \& Bare 2002. Keperawatan Medikal Bedah. Edisi 8. Vol 1. Alih Bahasa Agung Waluyo. Jakarta. EGC

Smeltzer \& Bare 2002. Keperawatan Medikal Bedah. Edisi 8. Vol 2, EGC. Jakarta.

Tamsuri A, 2007. Konsep dan Penatalaksanaan Nyeri. Jakarta. EGC

Wirya I, Sari MD, 2013, Pengaruh Pemberian Masase Punggung Dan Teknik Relaksasi Nafas Dalam Terhadap Penurunan Intensitas Nyeri Pada Pasien Post Appendiktomi Di Zaal C Rs HKBP Balige Tahun 2011, Jurnal Keperawatan HKBP Balige, Vol.1 No.1, Juni 2013 ISSN 2338-369091 